Article

\title{
Impacto do ENOS na Variabilidade da Coluna Total de Ozônio Sobre a Região Nordeste do Brasil - Parte 1: El Niño Canônico e Modoki
}

\author{
Daniel Milano Costa de $\operatorname{Lima}^{1}$ (D), Mateus Dias Nunes ${ }^{2}$, Glauber Lopes Mariano ${ }^{1}$ \\ ${ }^{1}$ Instituto de Ciências Atmosféricas, Universidade Federal de Alagoas, Maceió, AL, Brasil. \\ ${ }^{2}$ Centro de Previsão de Tempo e Estudos Climáticos, Instituto Nacional de Pesquisas Espaciais, \\ Cachoeira Paulista, SP, Brasil.
}

Recebido em: 1 de Julho de 2020 - Aceito em: 9 de Outubro de 2020

\begin{abstract}
Resumo
O objetivo deste trabalho é analisar a variação anual e os efeitos do modo de variabilidade atmosférica El Niño (Canônico e Modoki) na Coluna Total de Ozônio (CTO) sobre o Nordeste Brasileiro (NEB) entre 1997 e 2018 utilizando dados dos sensores Total Ozone Mapping Spectrometer (TOMS) e Ozone Monitoring Instrument (OMI). Foi constatada uma variação mensal média em toda área estudada com comportamento típico de domínio do ciclo anual na variabilidade sazonal, apresenta valor mínimo no mês de maio e máximo em outubro. Observou-se uma tendência de decaimento na série dos valores médios durante o período analisado. Análises de agrupamento revelaram que diferentes regiões da NEB possuem comportamentos e valores médios de CTO diferenciados. Análise de ondeletas expôs ciclos de doze meses de duração atuando na CTO em toda área estudada, ciclos de seis meses, demonstrando que o ciclo semianual domina a variabilidade sazonal em menores latitudes, e ciclos de dois-três anos, representando a importante atuação da Oscilação Quase Bienal (OQB). As médias das anomalias mostram que eventos El Niño afetam a CTO causando, predominantemente, diminuição de seus valores. Esses eventos em modalidade Modoki tem maior potencial em afetar a CTO que os Canônicos com anomalias negativas de maior intensidade.
\end{abstract}

Palavras-chave: sensoriamento remoto, análise de agrupamento, ENOS.

\section{Impact of ENSO on Variability of the Total Ozone Column Over the Northeast Region of Brazil - Part 1: El Niño Canonical and Modoki}

\begin{abstract}
The objective of this work is to analyze the annual variation and the effects of the atmospheric variability mode El Niño (Canonical and Modoki) on the concentration of the Total Ozone Column (TOC) on the NEB between 1997 and 2018 using data generated by the sensors Total Ozone Mapping Spectrometer (TOMS) and Ozone Monitoring Instrument (OMI). An average monthly variation was observed, with typical behavior of the annual cycle domain in the seasonal variability, presenting a minimum value in May and maximum in October. There was a declining trend in the series of average values for the entire area. Cluster analysis revealed that different regions of the study area have slightly different behaviors and mean values of the total ozone column. Wavelet analysis was used, which exposed cycles of twelve months in length throughout the studied area, six-month cycles, demonstrating that the semi-annual cycle dominates seasonal variability in lower latitudes, and also two to three years cycles, representing the important performance of the Quasi-Biennial Oscillation (QBO). Anomaly averages show that El Niño events affect TOC causing predominantly a decrease in their values. These Modoki events have a greater potential to affect TOC variations than canonical events, with negative anomalies of greater intensity.
\end{abstract}

Keywords: remote sensing, cluster analysis, ENSO.

\section{Introdução}

O ozônio atmosférico exerce uma função fundamental tanto no balanço radiativo do planeta (Xie et al.,
2008; Gilford e Solomon, 2016; Ming et al., 2017) quanto no papel de filtro de radiação no espectro do ultravioleta, principalmente UV-B, prejudicial aos seres vivos (Kirchhoff et al., 2000; Kim et al., 2013). Além disso, estudos

Autor de correspondência: Daniel Milano Costa de Lima, daniel-milano@hotmail.com 
observacionais e de modelagem atmosférica mostram o impacto das alterações do ozônio nos aspectos dinâmicos da alta troposfera e baixa estratosfera, como por exemplo na fração de nebulosidade (Grise et al., 2013), frequência de ciclones no hemisfério sul (Grise et al., 2014), alargamento da célula de Hadley e mudança da posição do jato subtropical (Kang et al., 2011), e regimes de precipitação (Gonzalez et al., 2014).

Embora as variações de ozônio a longo prazo sejam predominantemente dominadas por substâncias depletoras do ozônio (Polvani et al., 2011; Steinbrecht et al., 2018; Weber et al., 2018), as variabilidades dinâmicas de curto e longo prazo também influenciam significativamente nas variabilidades intrasazonal, interanual e de longo prazo do ozônio em latitudes médias (Zhang et al. (2015). Peres et al. (2017) e Toihir et al. (2018) mostraram estas variações de longo prazo a partir de modelos de regressão linear para diferentes forçantes de ozônio como por exemplo, El Niño-Oscilação Sul (ENOS), Oscilação Quase-Bienal (OQB), ciclo solar entre outros, utilizando dados de satélites de diferentes regiões (tropicais e subtropicais). Nesses estudos notou-se que o ciclo anual de ozônio é o modo de variabilidade predominante e apresenta uma assinatura meridional com máximos sobre as regiões subtropicais. Modos de variabilidades semianuais e semestrais são os mais presentes na região equatorial. Torna-se assim a circulação de grande escala fator importante no transporte $\mathrm{e}$ alocação de massas de ar ricas em ozônio.

A Circulação Brewer-Dobson (CBD) é uma circulação de transporte zonal na estratosfera que transporta o ar da região tropical em direção aos polos (Solomon, 1999). Estas circulações transportam o ozônio que se forma em maior parte na estratosfera tropical, a partir da fotodissociação de oxigênio molecular, para os extratrópicos e região polar (Abalos et al., 2015; Albers et al., 2017). A CBD pode ser afetada por modos de variabilidade interanual que influenciam na dinâmica da baixa estratosfera, como por exemplo a OQB (Chehade et al., 2014; Tian et al., 2017; Diallo et al., 2018) e o ENOS (por exemplo Braesicke et al., 2011; Nowack et al., 2017; Manatsa e Mukwada, 2017).

O ENOS, um fenômeno tropical do Pacífico caracterizado por componentes oceânicos (El Niño) e atmosféricos (oscilação sul) acopladas, fonte importante de variabilidade interanual na atmosfera bem como na distribuição de rastreadores atmosféricos, como o ozônio estratosférico (Oliveira e Satyamurty, 1998; Ambrizzi, 2003). Maiores definições sobre este fenômeno em Allan (1996) e Philander (1990). Qualquer leve perturbação no ozônio estratosférico inferior induz potenciais anomalias na circulação e temperatura da troposfera que são suficientemente fortes para impactar a superfície (Zhang et al., 2015). Estas avaliações do impacto do ENOS nas distribuições dos constituintes atmosféricos da região tropical são focadas principalmente em ozônio (Wang et al.,
2011; Manatsa e Mukwada, 2017; Diallo et al., 2018) e vapor d'água (Xie et al., 2011). Segundo Manatsa e Mukwada (2017), os resultados indicam que durante os extremos do ENOS a Circulação de Walker (CW) e a CBD estão relacionadas a alterações mais baixas do ozônio estratosférico e consequentemente da Coluna Total de Ozônio (CTO) a leste no Pacífico equatorial (Xie et al., 2014).

Tendo conhecimento que a concentração de ozônio na atmosfera é inversamente proporcional a quantidade de radiação UV que atinge a superfície terrestre e que a sazonalidade e modos de variabilidade atmosféricos modulam a distribuição de ozônio (Solomon, 1999; Fioletov, 2008), se revela vital compreender quais os períodos e quais fenômenos diminuem as concentrações da CTO, tornando mais perigosa a exposição à radiação solar direta. A região Nordeste do Brasil (NEB) é uma área localizada próximo ao equador terrestre, dentro da região tropical. Uma grande quantidade de atividades humana envolvendo exposição à radiação solar são realizadas neste território, tornando assim o estudo da variação da concentração de ozônio sobre a região imprescindível. Portanto, o objetivo desse estudo é avaliar a variabilidade da CTO sobre todo o NEB em escalas de tempo mensal e interanual, obter a concentração média, avaliar regiões dentro da área de estudo com diferentes comportamentos de variações e analisar a influência do modo de variabilidade ENOS, com ênfase nos El Niños dos tipos Canônico e Modoki.

\section{Materiais e Métodos}

Para a avaliação das concentrações da CTO na região do NEB foram obtidos dados da CTO gerados pelos sensores Total Ozone Mapping Spectrometer (TOMS) e Ozone Monitoring Instrument (OMI). Estes dados são disponibilizados pela NASA (National Aeronautics and Space Administration) através da plataforma GIOVANNI, onde os dados são compilados por resoluções espaciais e espectrais, séries temporais e diferentes plataformas com sensores a bordo de satélites. A resolução espacial de ambos os sensores são de $1^{\circ} \times 1^{\circ}$ para a região do NEB, compreendida nas coordenadas geográficas, $1^{\circ} \mathrm{S}$ à $19^{\circ} \mathrm{S} \mathrm{e}$ $48^{\circ} \mathrm{W}$ à $35^{\circ} \mathrm{W}$. Como metodologia para obtenção de dados abrangendo todo NEB foram definidas subáreas de estudo dividindo todo a região do NEB em 142 quadrantes seccionados pelas linhas de coordenadas geográficas terrestres de latitude e longitude cobrindo toda área de estudo para os quais foram obtidas séries temporais diárias de valores de CTO.

O período analisado para os dados da CTO foi de 1997 a 2018 (TOMS 1997-2005 e OMI 2005-2018) onde as falhas diárias na série, que representam $15,8 \%$ dos dados obtidos, foram preenchidas utilizando interpolação entre o dia anterior e o dia consecutivo utilizando a técnica matemática "spline", sendo esta mais eficiente por usar 
vários polinômios de grau baixo para reconstituir a curva de valores de CTO. Mais detalhes sobre esta técnica em Lopes (2018). Das médias mensais obtidas foram gerados diagramas Hovmöller que revelam o comportamento latitudinal da CTO em escala temporal mensal. As séries temporais dos 142 quadrantes de $1^{\circ} \times 1^{\circ}$ sobre a região de estudo foram submetidas a uma análise de agrupamento (cluster), um processo que agrupa dados com características semelhantes (Wilks, 2011), com o objetivo de identificar regiões com variações semelhantes da CTO. Para esse trabalho foi determinado que a análise resultaria em cinco grupos distintos, valor escolhido de forma subjetiva pelo autor, requisito do teste não hierárquico k-means aplicado, após testes com o algoritmo de separação dos grupos.

As características temporais dos grupos foram analisadas através da técnica de análise de ondeletas, a fim de identificar ciclos nas séries temporais e suas respectivas durações. O método constitui em analisar as componentes da variabilidade de séries temporais e apresentá-la em vários níveis tempo-frequência. Para maiores informações sobre essa técnica ver Torrence (1998) e Peres (2013).

No estudo da influência do modo de variabilidade ENOS - El Niño Canônico e Modoki a identificação dos meses sobre influência ou não do evento foi realizada utilizando os índices The Oceanic Niño Index (ONI) e El Niño Modoki Index (EMI), este disponibilizado pela JAMSTEC (Japan Agency for Marine-Earth Science and Technology), onde valores menores ou iguais à $-0,5$ indicam ocorrência de La Niña (Canônica/Modoki), e maiores ou iguais à 0,5 indicam ocorrência El Niño (Canônica/ Modoki) (NCEP, 2018). Os valores restantes são considerados períodos neutros (sem atuação). Foram obtidas as médias mensais e anomalias dos períodos com e sem a ocorrência do fenômeno El Niño (Canônico e Modoki). Maiores detalhes sobre parâmetros para definição da ocorrencia e da modalidade, Canônica ou Modoki, dos fenômenos ENOS estudados são esclarecidos por Takahashi (2011) e listas de meses com ocorrência destes fenômenos disponíveis nos sites da NOAA e JAMSTEC. Na análise mensal, para cada mês foram gerados 142 valores de anomalias, a mesma quantidade de quadrantes obtidos para a área de todo NEB. Portanto, para 12 meses com 142 valores de quadrantes cada tem-se 1704 registros ao ano. Estes valores são importantes quando comparamos a quantidade de quadrantes, apresentadas nos resultados, com anomalias positivas e negativas durante às ações ou não-ações do modo de variabilidade estudado.

Portanto, para análise e discussão dos dados estudados apresenta-se gráficos de áreas dos dados de anomalias com resolução temporal mensal e total, para análise espacial; diagramas Hovmöller da variação interanual da CTO por latitude; histogramas contendo análise dos valores de anomalia de cada quadrante, para compreender as intensidades das anomalias do modo; cálculos de porcentagem da quantidade de quadrantes apresentando anomalias positivas ou negativas, expondo se o evento tende, predominantemente, a aumentar ou diminuir a CTO.

\section{Resultados e Discussões}

\subsection{Análise de clusters para a variabilidade interanual da CTO entre os quadrantes do NEB}

A avaliação do comportamento da variabilidade interanual e sazonal da CTO para toda a região do NEB é apresentada na Fig. 1. A variabilidade interanual para o período entre 1997-2018 é representada na Fig. 1a e o ciclo sazonal da CTO no NEB entre os anos de 1997 e 2018 é representado na Fig. 1b. A equação da reta de regressão linear apresenta coeficiente angular negativo, indicando tendência de diminuição dos valores médios de CTO. É possível observar que os valores da CTO no NEB no período analisado, se concentram tipicamente entre 245,0 UD e 280,0 UD, reforçados por Sousa et al. (2020) com alguns anos atípicos podendo variar de 240,0 UD até 290,0 UD (Fig. 1a). Foi observado a existência de um ciclo semianual de variação da CTO tendo seus valores mínimos no trimestre abril-maio-junho de cada ano e os mais altos nos trimestres setembro-outubro-novembro, consoante com sLima (2018) com período de estudo de 2005 a 2015 para a mesma região, semelhante ao observado por Lopo et al. (2013) no período 2001 a 2009 e Sousa et al. (2020) no período de 1978 a 2013. Neste último, os resultados mostram o comportamento da CTO na cidade de Natal-RN, onde as tendências à longo prazo da CTO corroboram com o encontrado na região do NEB representadas pela Fig. 1a.

O ciclo semianual da região do NEB mostra o comportamento da CTO em cada mês, variabilidade dos valores encontrados corrobora com os obtidos por Sahai et al. (2000) e Sousa et al. (2020). Nesse ciclo há grande influência dos modos de variabilidade ENSO, no período entre 1997/1998, e da OQB.

A variação da CTO no NEB não é tão acentuada como visto em Sahai et al. 2000, Lopo et al. (2013) e Sousa et al. (2020), porém apresenta uma curva suave com variação de com aproximadamente $23,0 \mathrm{UD}$, seu valor mínimo é no mês de maio (250,7 UD) e o valor máximo no mês de outubro (274,1 UD). No primeiro trimestre do ano, janeiro-fevereiro-março, os valores de CTO permanecem quase estacionários entre 259,0 UD e 260,0 UD, nos meses seguintes apresenta uma intensa diminuição até atingir o valor mais baixo, em maio, com 250,7 UD. Após esse período, ocorre um aumento constante até o mês de outubro, onde atinge o valor máximo anual com 274,1 UD. Novembro e dezembro apresentam diminuição gradual dos valores, 268,5 UD e $262,8 \mathrm{UD}$, respectivamente. Este ciclo anual é observado ao longo de latitudes mais altas, entretanto com maiores variações como mostrado em Peres et al. (2017) e Dias Nunes (2017; 2020). 


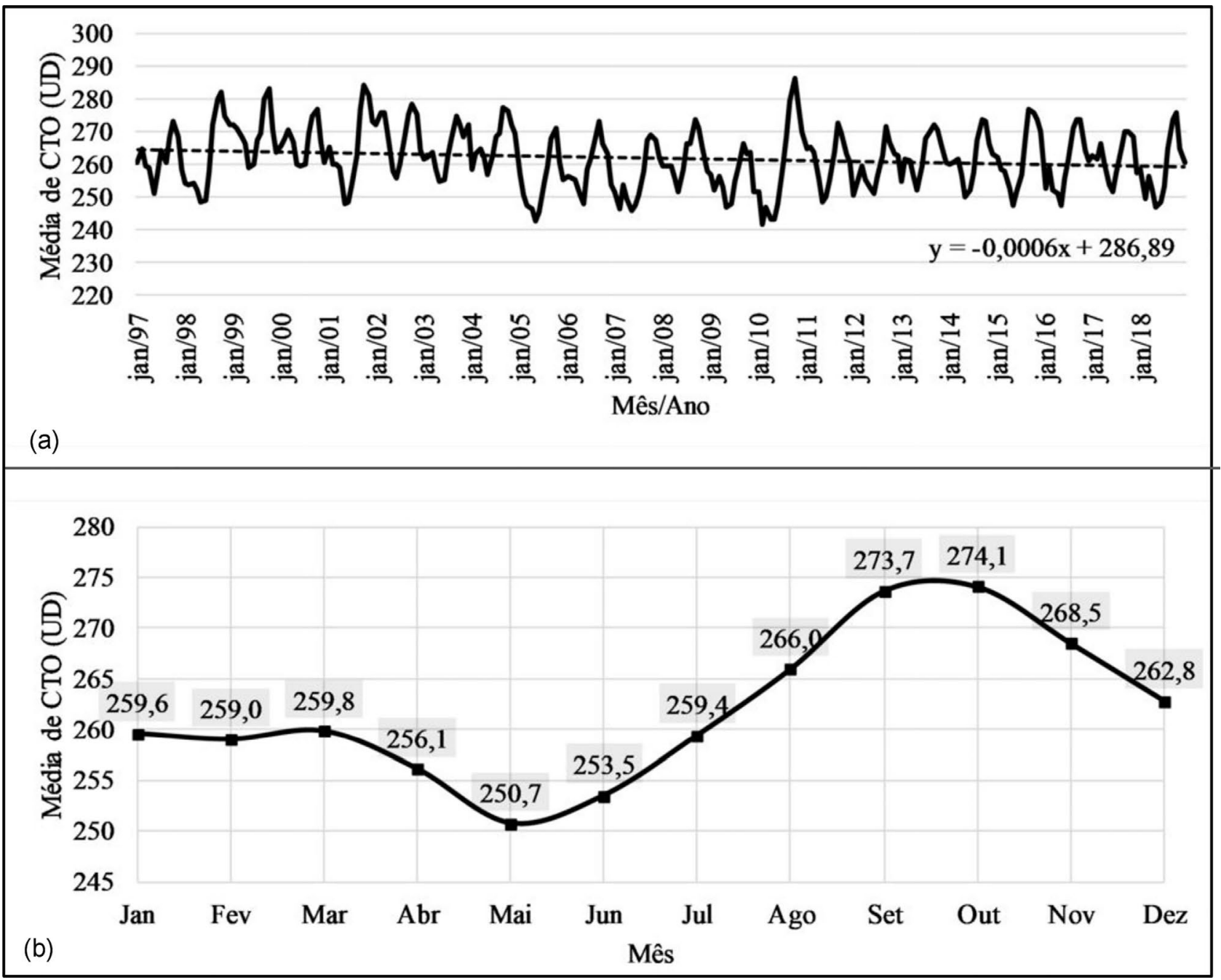

Figura 1 - Médias da Coluna Total de Ozônio (CTO) para toda área do NEB entre os anos de 1997 e 2018. Acima, variabilidade interanual e linha de tendência (a), abaixo, ciclo mensal (b).

Performando a análise de cluster pelo método não hierárquico k-means para séries temporais mensais dos 142 quadrantes obtemos o resultado gráfico apresentado na Fig. 2. A análise alocou os quadrantes em cinco grupos com base em suas semelhanças na variação das séries de valores médios de CTO de todo período de estudo com resolução temporal mensal. O grupo A está localizado no norte do NEB, cobre a parte norte os estados do Maranhão, Piauí e Ceará. O grupo B está no centro-oeste, cobre maior parte do Piauí, do Maranhão e pequenas parcelas do norte da Bahia, do oeste de Pernambuco e do interior do Ceará. O grupo $\mathrm{C}$ abrange parte do litoral leste do NEB e inclui os estados do Rio Grande do Norte, Paraíba, Pernambuco, Alagoas e Sergipe. O interior da Bahia e pequenas áreas do Maranhão e do Piauí estão sobre cobertura do grupo D. Por fim, o litoral da Bahia e pequena parte de Sergipe estão incluídas no grupo E.

O grupo A, localizado próximo ao equador terrestre, com latitude máxima em $1^{\circ} \mathrm{S}$ e mínima em $6^{\circ} \mathrm{S}$ e longi- tudes mínimas em $37^{\circ} \mathrm{W}$ e máximas em $48^{\circ} \mathrm{W}$, cobre parte do litoral norte do NEB. A Fig. 3a, mostra que nos meses de dezembro, janeiro e fevereiro, verão no hemisfério Sul, os valores médios da CTO são inferiores às médias para todo NEB para os quadrantes deste grupo. Março e novembro apresentam valores próximos à média do NEB e os meses restantes, acima. A maior média ocorre no mês de setembro, com 277,0 UD, e a menor em maio (254,0 UD). A análise de ondeletas (Fig. 3a) foi capaz de identificar ciclos em séries de dados e suas respectivas durações, na qual constatou a presença de ciclos com aproximadamente seis meses, um ano e entre dois e três anos de duração. O grupo B (Fig. 3b), localizado na região interiorana do NEB, ao sul do grupo B, entre as latitudes $5^{\circ} \mathrm{S}$ e $10^{\circ} \mathrm{S}$ e longitudes $39^{\circ} \mathrm{W}$ e $48^{\circ} \mathrm{W}$, exibe médias mensais muito próximos às médias para todo o NEB. Apresenta valor máximo em setembro, com 274,0 UD, e mínimo em maio, 251,0 UD. Na análise de ondeletas há presença de ciclos com seis meses, um ano e 2-3 anos de 


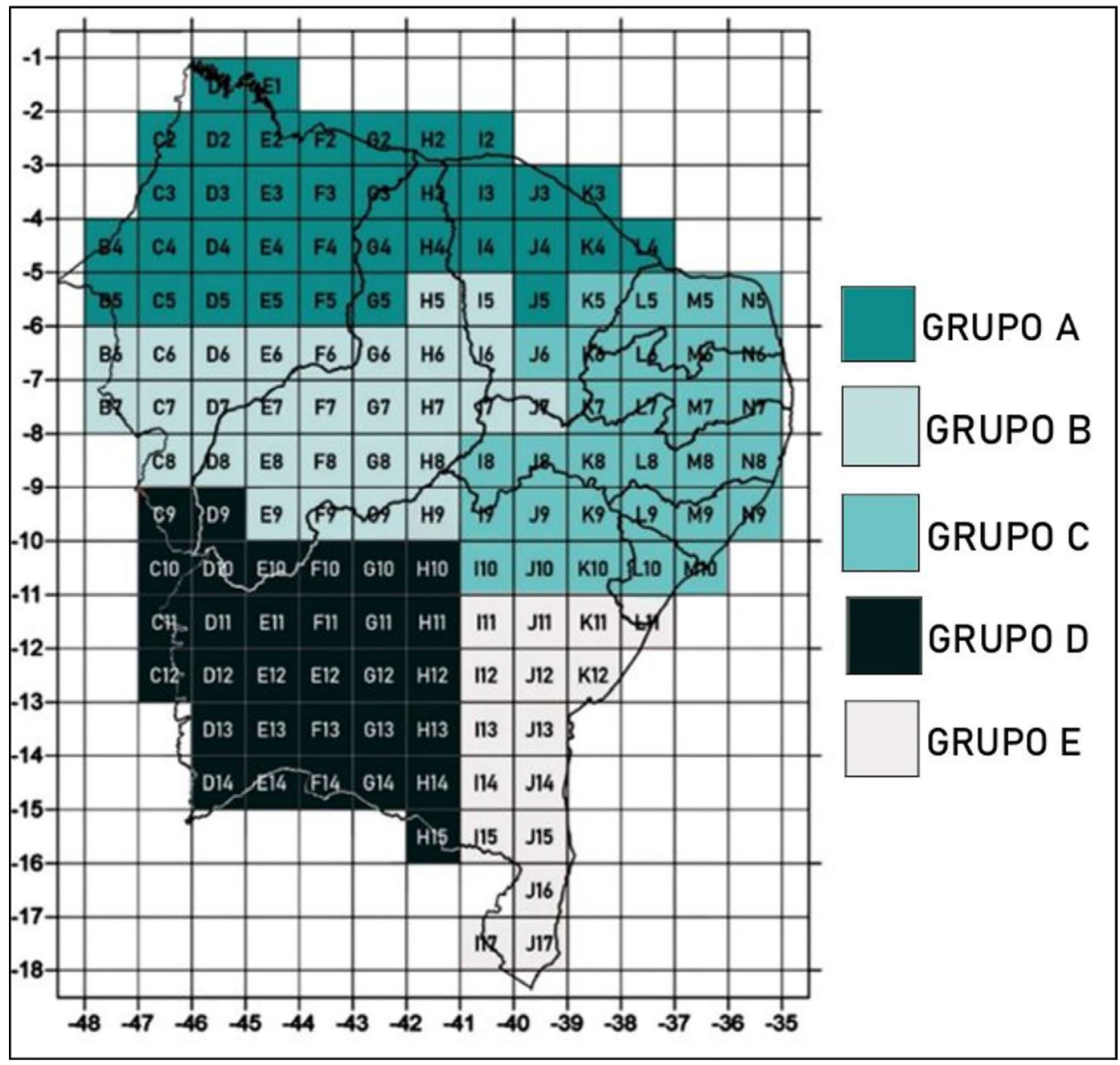

Figura 2 - Grupos de quadrantes definidos pela análise de cluster na área do NEB.

duração, mas este último perde intensidade quando comparado ao identificado no grupo A (Fig. 3a), estando este em maiores latitudes. Já o grupo C (Fig. 3c), mostra um agrupamento que está presente entre latitudes próximas às do grupo $\mathrm{B}$, no intervalo de $5^{\circ} \mathrm{S}$ a $11^{\circ} \mathrm{S}$ e entre as longitudes $35^{\circ} \mathrm{W} \mathrm{e} 41^{\circ} \mathrm{W}$, cobrindo parte do litoral leste e norte do NEB. Os valores médios para esta área são sutilmente superiores à média para o NEB durante todo o ano, sendo essa discrepância mais intensa nos meses de dezembro, janeiro, fevereiro, março e abril. Apresenta valor máximo em outubro (275,0 UD) e mínimo em maio (251,0 UD). Os mesmos ciclos identificados no grupo B estão presentes nessa região e com intensidades aproximadas. Quanto ao Grupo D, este conjunto de quadrantes está localizado predominantemente sobre o interior do estado da Bahia, nas latitudes de $9^{\circ} \mathrm{S}$ a $16^{\circ} \mathrm{S}$ e longitudes de $41^{\circ} \mathrm{W}$ a $47^{\circ} \mathrm{W}$. Neste grupo o sinal do ciclo de 2-3 anos não está presente na análise de ondeletas, onde o ciclo de seis meses perde força, enquanto o de um ano mantém suas características apresentadas nos grupos A, B e C.
Por fim, o grupo E, situado entre latitudes próximas às do grupo $\mathrm{D}$, de $11^{\circ} \mathrm{S}$ a $18^{\circ} \mathrm{S}$, no intervalo das longitudes entre $37^{\circ} \mathrm{W}$ e $41^{\circ} \mathrm{W}$, cobrindo todo litoral da Bahia e parte de Sergipe. Este grupo possui valores acima da média do NEB entre abril e setembro (Fig. 3e) e abaixo nos meses restantes, apresentando valor máximo em outubro, com 276,0 UD, e mínimo em maio, 249,0 UD. Foram observados os ciclos com período de seis meses e um ano de duração presentes na análise de ondeletas, no entanto, apresentando intensidade inferior em relação aos outros grupos. Na região do NEB há um influência da OQB na variabilidade de CTO, em todos os quadrantes é observada a periodicidade no espectro normalizado de 8 a 16 meses provocada por esse modo de variabilidade, corroborando com as afirmações feitas por McPeters et al. (1998) e Baldwin et al. (2001). A modulação da OQB é o principal modo de variabilidade interanual de CTO por mostrar as maiores intensidades através contornos de nível de significância (contornos pretos). 


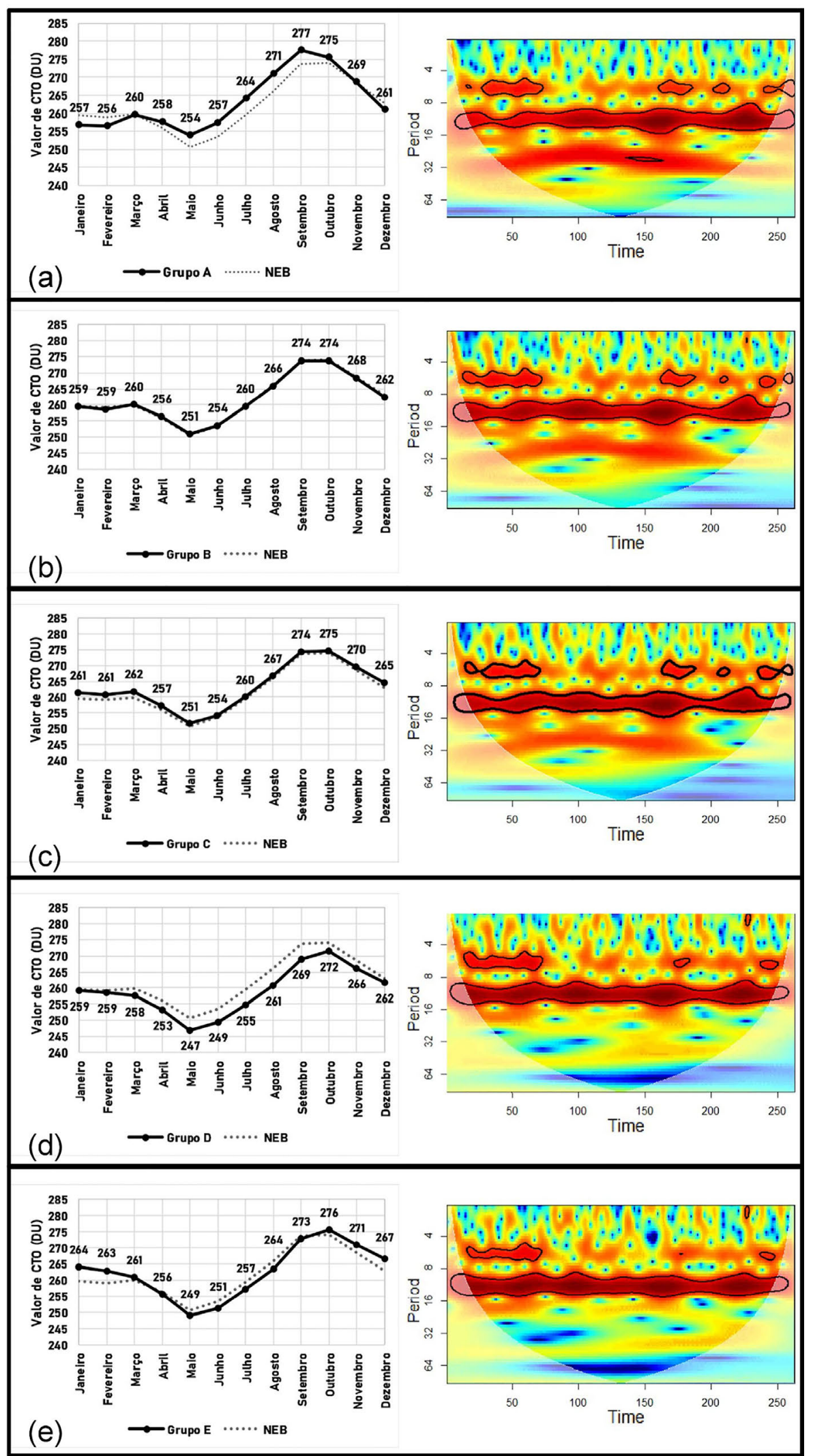

Figura 3 - Na coluna esquerda, médias mensais da CTO de cada grupo comparadas às respectivas médias mensais para toda área do NEB. Na direita, análise de ondeletas para toda série de valores de média mensal entre todos os quadrantes de um mesmo grupo. Nas linhas, grupo A (a), grupo B (b), grupo C (c), grupo D (d) e grupo E (e). 
Os ciclos de 64 meses que compõem o cone de influência estão associados à periodicidade de atuação do ENSO (Reid, 1994).

A análise da distribuição de intensidade das anomalias de todos os quadrantes é exposta na Fig. 4 onde são mostrados os aspectos da CTO sem a atuação dos ENOS (Fig. 4a) e com as atuações dos El Niños Canônico e Modoki (Fig. 4b e 4c, respectivamente).

Analisando os valores das médias mensais de todos os quadrantes através de histograma (Fig. 4a) fica evidenciado que a maior parte das anomalias registradas são de pouca intensidade quando se observa 583 quadrantes com valores entre $-0,5$ e 0,5 , totalizando $32,2 \%$ de todos os va-
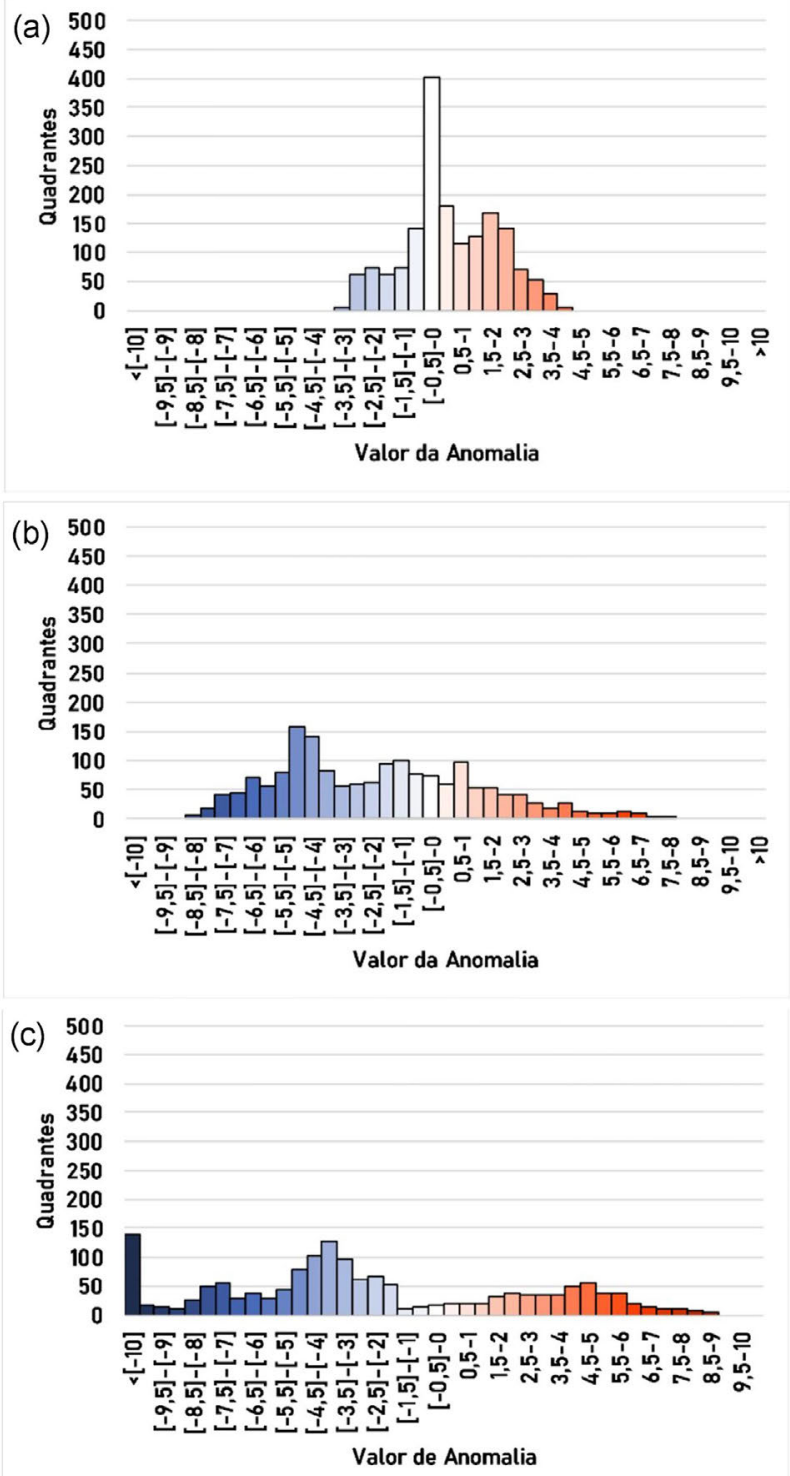

Figura 4 - Histograma dos valores médios mensais das anomalias de todos os quadrantes. Os períodos analisados são: sem influência de ENOS (a), sob influência de El Niño - Canônico (b) e sob influência de El Niño - Modoki (c). lores registrados. As anomalias positivas somam 815 registros e estão distribuídas em valores de 0,0 a 4,0 , representando $48 \%$ de todos os valores registrados. As anomalias negativas representam $52 \%$ do montante, com 889 registros de valores entre 0 e $-3,5$. Os intervalos do histograma para análise do período com influência do ENOS Canônico (Fig. 4b) que apresentam as maiores quantidades de valores de anomalia registrados, estão entre $-4,0$ e $-4,5$ ( 141 eventos) e entre $-4,5$ e -5 (158 eventos). Juntos representam $25,3 \%$ dos valores negativos registrados. Quanto às anomalias positivas, variam de $0 \mathrm{a}$ 7,7 (478 registros), 71,7\% dos valores estão entre 0 e 3,0 e os $28,3 \%$ restantes entre 3,0 e 7,7 . Durante a ação desse fenômeno de variabilidade, a maior parte das anomalias são negativas representando $72 \%$ de todos os registros efetuados, onde os valores variam entre 0 e $-8,2$ (1226 registros). Constata-se que $42,8 \%$ dos registros estão entre 0 e $-3,0 ; 37,5 \%$ estão entre $-3,0$ e $-5,0$; e $19,5 \%$ possuem valores menores que $-5,0$.

Quando analisado a anomalia da CTO durante a ocorrência do ENOS Modoki percebemos anomalias negativas, com valores variando entre 0 e $-17,2$, representando $69 \%$ de todos registros (1079 ocorrências) (Fig. 4c). Ainda sobre as negativas, segundo o histograma, 139 possuem valores menores que $-10,0$, diferentemente do fenômeno canônico que não apresenta valores menores que -8,2. 20,9\% estão presentes no intervalo entre 0 e $-3,0$, $37,4 \%$ entre $-3,0$ e $-5,0$, e $41,6 \%$ menores que $-5,0$. Anomalias positivas estão alocadas entre 0 e 8,8 , representam $31 \%$ dos valores obtidos.

\subsection{Influência do ENOS na variabilidade interanual da CTO no NEB}

A variabilidade da CTO para o período entre 19972018 na região do NEB é mostrada na Fig. 5a, onde é possível observar, no painel superior à média total para o período estudado, e no painel inferior, o diagrama Hovmöller que mostra a variabilidade sazonal para o mesmo período. Vale ressaltar que esse tipo de análise (diagrama Hovmöller) de variabilidade interanual ou sazonal da CTO é muito comum para análises da distribuição de ozônio em escala global, tendo em seus eixos a escala temporal meses versus latitudes (variação sazonal global). A exemplos os resultados mostrados nos estudos de Divakarla et al. (2008), De Artigas e De Campra (2010) e Davis et al. (2017), no entanto, diferentemente destes, o presente estudo focaliza somente a região do NEB. Os valores da CTO ficam entre 240 UD e 280 UD, uma variação de $\sim 14 \%$ na região do NEB. As variações mais significativas ocorrem no período entre os meses de agosto e novembro entre as latitudes de $1^{\circ} \mathrm{S}$ até $18^{\circ} \mathrm{S}$, período em que há um aumento significativo das médias de CTO nas regiões de latitudes médias devido a presença do Vórtice Polar Antártico, que age como uma barreira impedindo a chegada dos conteúdos de ozônio distribuídos pela CBD na 


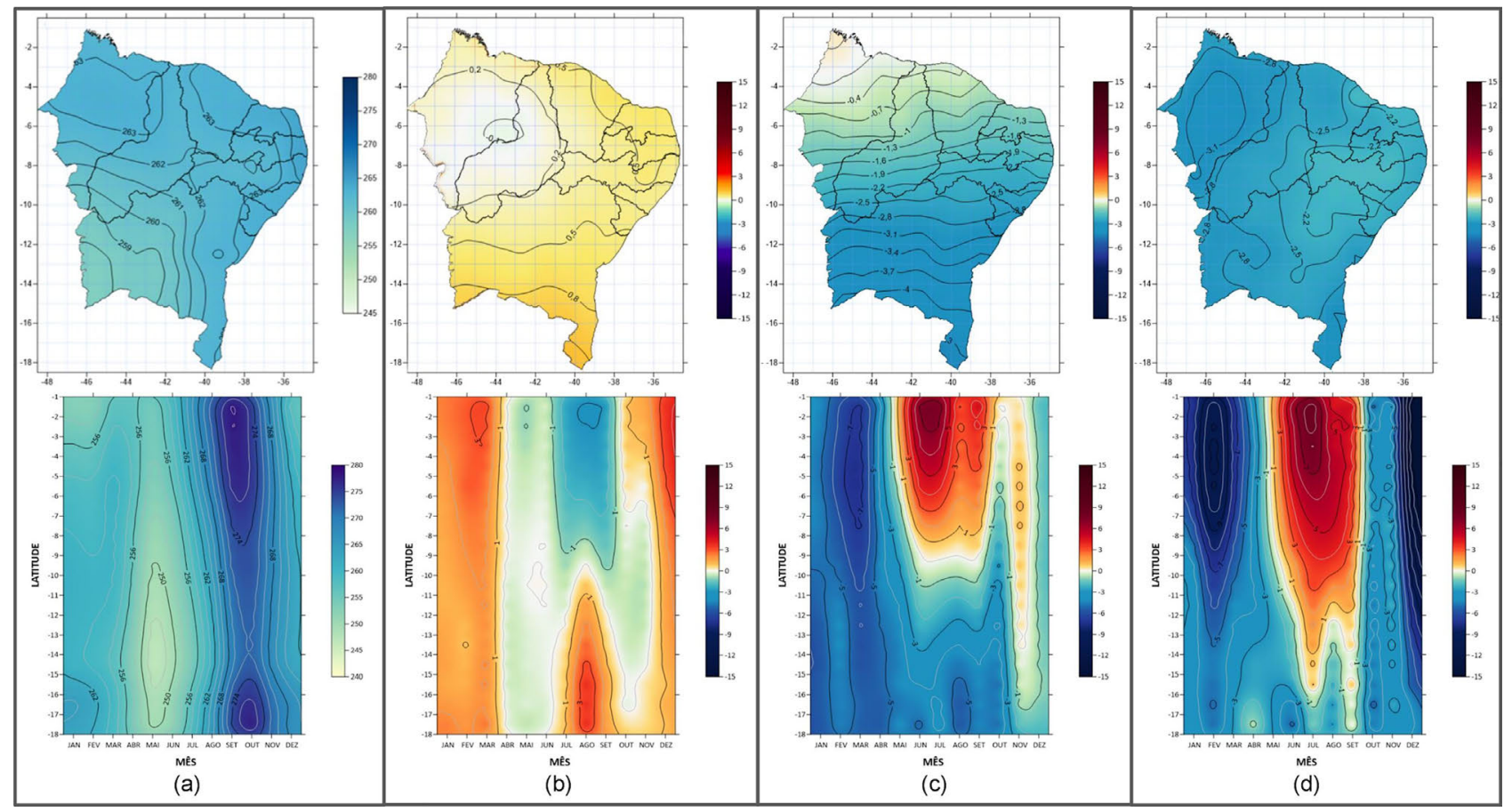

Figura 5 - Nas colunas, variabilidade CTO representada pelos valores médios do período entre 1997 e 2018 (a), anomalias espaciais para todo NEB durante períodos sem influência do ENOS (b), sob influência de El Niño Canônico (c) e El Niño Modoki (d). Na linha superior, gráficos de área de todo NEB. $\mathrm{Na}$ inferior, diagrama Hovmöller com média mensal dos valores dos quadrantes de mesma latitude.

região polar, e assim, os conteúdos de ozônio ficam aprisionados na região das latitudes médias semelhantes ao exposto em Peres et al. (2013) e Dias Nunes et al. (2020). De abril à maio todas as latitudes apresentam diminuição dos valores médios. A diminuição é mais intensa à oeste da Bahia, com valor mínimo de 246,6 UD, menor valor registrado dentre todas as médias latitudinais de todos os meses, aumentando à medida que nos afastamos da região. Calvo et al. (2010) e Wang et al. (2011) encontraram indícios que durante eventos El Niño a CBD sofre intensificação, afetando o transporte de massas de ar da região tropical, ricas em ozônio, diminuindo ou aumentando a concentração desse gás na região equatorial.

As anomalias da CTO na região do NEB em função do ENOS são observadas na Fig. 5, onde é mostrada a variabilidade da CTO nos anos sem a influência de ENOS (Fig. 5b), sob influência de El Niño Canônico (Fig. 5c) e sob influência de El Niño Modoki (Fig. 5d). Dentre os três cenários citados, o cenário sem influência de ENOS é o único que apresenta em toda a região do NEB anomalias positivas, o que mostra que sob a atuação de ENOS há uma tendência de diminuição da CTO na região do NEB. Isso é relatado por Calvo et al. (2010), que afirma haver uma intensificação da CBD durante estes eventos fazendo que exista maior transporte de massas de ar ricas em ozônio da região equatorial para regiões de maiores latitudes. Entretanto é possível observar uma característica inversa nos meses de junho a outubro entre $1^{\circ} \mathrm{S}$ e $10^{\circ} \mathrm{S}$ no perío- do sem atuação de ENOS (Fig. 5b) e nos períodos de El Niño Canônico e El Niño Modoki, (Fig. 5c e Fig. 5d, respectivamente). No período sem atuação do ENOS há o predomínio de uma anomalia negativa na região entre $1^{\circ} \mathrm{S}$ e $10^{\circ} \mathrm{S}$, chegando à aproximadamente $-4,0 \mathrm{UD}$ em áreas próximas ao equador, entretanto anomalias positivas são observadas nos períodos de El Niño Canônico e Modoki, chegando à aproximadamente $+10,0$ UD. Entretanto, quando analisado todo o período da série estudada, há predomínio de anomalias negativas na região do NEB.

Muitos estudos, como Grimm (2003) e Grimm (2004), avaliaram o comportamento sazonal do ENOS quanto às diferentes características apresentadas na circulação de grande escala entre as estações. Já o impacto do padrão sazonal do ENOS na variabilidade da CTO foi observado recentemente por Zhang et al. (2015) e Manatsa et al. (2017). A avaliação do impacto sazonal do ENOS na variabilidade da CTO é abordada na Fig. 6, em que são avaliados os trimestre Dezembro-Janeiro-Fevereiro (DJF) e Junho-Julho-Agosto (JJA), onde cada trimestre é representado pelos períodos total, de 1997 até 2018, período sem influência de ENOS e períodos sob influência de El Niño Canônico e Modoki. Para cada trimestre são apresentados os valores médios e as anomalias da CTO de cada período (Fig. 6).

Primeiramente foi analisado o trimestre DJF para os diferentes períodos. Com relação aos valores médios de cada período, o período de neutralidade apresenta leve di- 


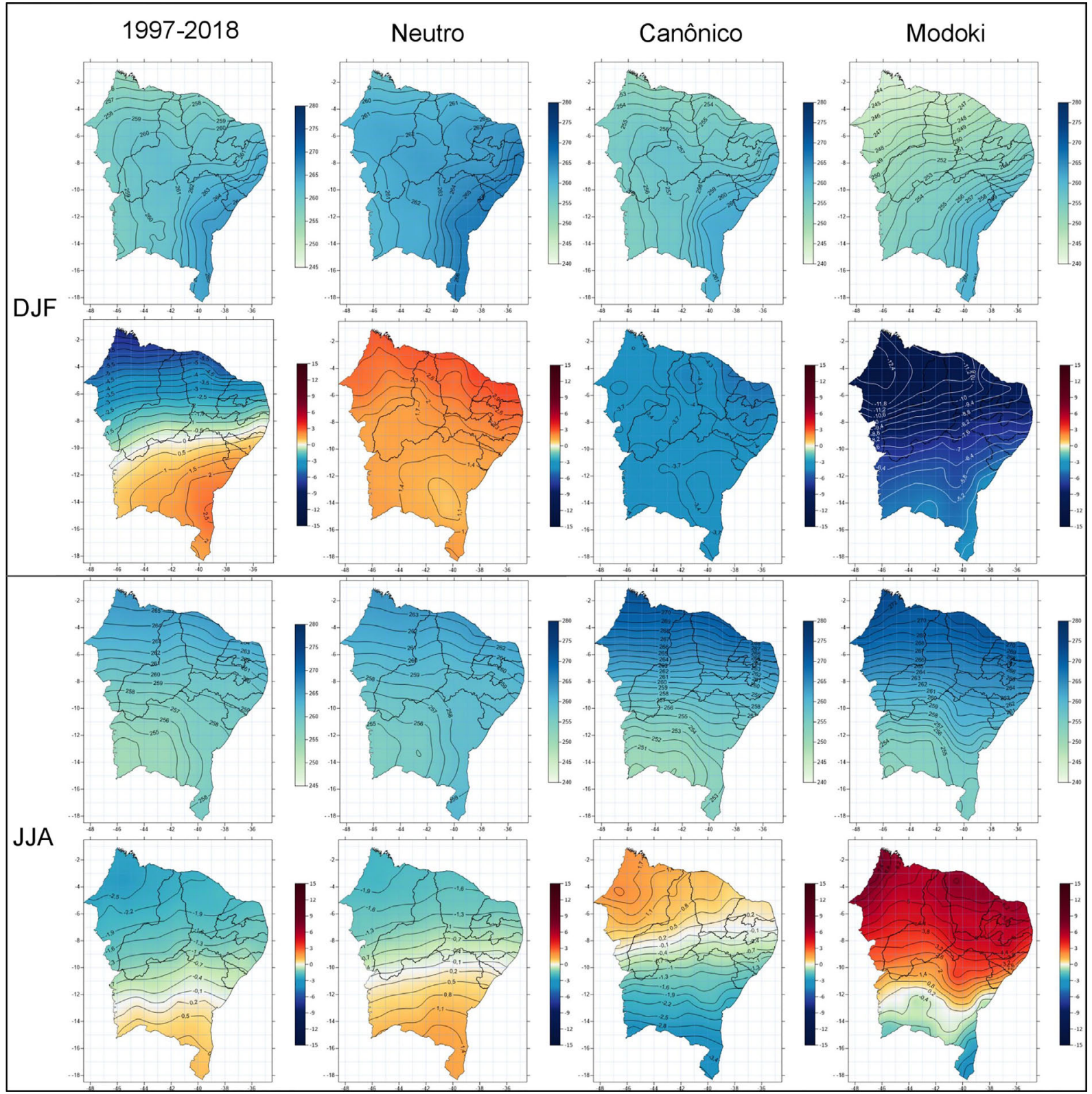

Figura 6 - No painel superior e inferior, valores médios sazonais e anomalias da CTO sobre a área do NEB. Nas colunas, valores médios para os períodos: de 1997 a 2018 (a); sem ocorrência de ENOS (b); com ocorrência de El Niño - Canônico (c); com ocorrência de El Niño - Modoki (d). Nas linhas superiores de cada painel, valores para trimestre DJF, e nas inferiores, para trimestre JJA.

vergência com relação ao período total e com a influência dos El Niño Canônico e Modoki. A região da costa do NEB apresenta em todos os períodos (de neutralidade ou sob influência de ENOS) os maiores valores da CTO durante o trimestre DJF, onde os menores valores são encontrados na região mais ao norte do NEB com leve declínio para o interior do continente. Com relação às anomalias de CTO entre os quatro períodos analisados, destaca-se os valores anômalos positivos para o período total e para o período neutro, tendo a região que vai do estado de Pernambuco até o norte do Maranhão os maiores valores de anomalia, chegando a 5,0 UD. Enquanto isso, nos perío- dos de atuação de ENOS (tanto Canônico quanto Modoki) os valores de anomalias são negativos. Nota-se que para o El Niño Modoki há uma mais acentuada variabilidade da CTO, o que pode ser causado pelas variações na CBD promovidas pela influência do ENOS, diferente do que acontece nos períodos total e neutro (Zhang et al., 2015; Diallo et al., 2019). Vale ressaltar que durante a atuação do ENOS Canônico a CTO apresenta uma maior homogeneidade na região do NEB, semelhantes ao observado por Zhang et al. (2015).

No trimestre JJA há uma inversão dos maiores valores da CTO no NEB quando comparado ao trimestre 
DJF, primeiramente devido ao diferente comportamento e intensificação da CBD durante estes períodos, como mostrado em Zhang et al. (2015) e Diallo et al. (2019). As maiores concentrações da CTO são observadas na região norte do NEB (mais próximas ao equador), ou seja, em menores latitudes, porém os menores valores da CTO estão localizados na região oeste do estado da Bahia. Com relação às anomalias de $\mathrm{CTO}$, novamente como observado no trimestre DJF, há um comportamento inverso dos períodos total e sem atuação de ENOS quando comparados aos períodos de ENOS Canônico e Modoki (Zhang et al., 2015). Nos períodos total e sem ENOS foi observada a presença de um dipolo de anomalia da CTO no NEB onde a faixa entre $11^{\circ} \mathrm{S}$ e $13^{\circ} \mathrm{S}$ limita os valores positivos e negativos das anomalias, estando os valores positivos abaixo desta faixa e os valores anômalos negativos, acima. Nos períodos de atuação do El Niño Canônico e Modoki este dipolo apresenta-se invertido com relação aos outros dois períodos, onde agora, os valores anômalos positivos encontram-se na parte mais ao norte (Xie et al., 2014; Zhang et al., 2015).

Um ponto importante desta análise é observar que para o ENOS Canônico há um predomínio dos valores negativos com os com valores próximos de zero nas proximidades de $8^{\circ} \mathrm{S}$, ao contrário do que ocorre no período de ENOS Modoki em que há um predomínio de valores positivos de anomalia em quase todo o NEB, apresentando apenas a metade sul do estado da Bahia valores negativos. Este comportamento ocorrido no NEB é diferente do observado na região do pacífico equatorial oriental (Xie et al., 2014; Zhang et al., 2015), que apresenta uma redução acentuada dos conteúdos de ozônio em relação a outras áreas da região tropical. Semelhante ao encontrado por Xie et al. (2014), notou-se que o El Niño Modoki tem maior potencial em afetar as variações da CTO do que o El Niño Canônico, tornando o período de atuação do Modoki o principal promotor de variações de ozônio na região do NEB dentre os períodos analisados. Para evidenciar a diferença entre as duas modalidades (Canônico e Modoki), a Fig. 7 expõe os valores mensais máximos, mínimos e a média das anomalias entre todos os quadrantes. Esta distribuição mensal mostra que as maiores anomalias são encontradas nos meses que compõem o trimestre JJA, o que concorda com a Fig. 6, quando comparadas as duas fases do ENOS, mostrando uma maior amplitude na modalidade Modoki quando comparada ao El Niño Canônico.

A Fig. 7 também mostra que na região do NEB, em baixas latitudes e no período do inverno ao início da primavera, há uma tendência aumento dos valores de CTO, o que é associado a atuação da CBD na estratosfera a qual a intensidade do transporte de massas pode variar causando acúmulo de ozônio nessas regiões de anomalias positivas, porém, os reflexos desse fenômeno são observados em todo NEB (London, 1985; Solomon 1999; Dias Nunes, 2017). Estas variações são confirmadas por Sousa et al.
(2020) que mostra a variação sazonal bem como os desvios padrões mensais. Entretanto, aqui ressaltamos que durante as análises de variações mensais e desvios padrões é observada a atuação de fenômenos El Niño, em suas fases Canônico e Modoki, potencializando as variações da CTO. A exemplo, é observado que os meses de junho, julho e agosto apresentam alterações acentuadas nos valores médios da CTO em períodos sob atuação destes modos de variabilidade quando comparados a uma longa série temporal como mostrado em Sahai et al. (2000) e Sousa et al. (2020). Para ocorrência de El Niño (Canônico e Modoki) nos meses entre Dezembro e Março é observado diminuição da CTO na região tropical em decorrência das alterações nos padrões de circulação em grande escala. Esses padrões são caracterizados por um enfraquecimento dos ventos alísios provocado por esse modo de variabilidade, gerando aceleração da $\mathrm{CBD}$, o que leva a diminuição dos valores da CTO nos trópicos e aumento nos extratrópicos (Reed et al., 1961). Existe uma dependência entre os valores da CTO nas regiões de latitudes médias e em parte da região tropical aos eventos ENOS (Canônico e Modoki) em escala sazonal. Este efeito pode ser associada às alterações em processos de dinâmica atmosférica que modula as concentrações de ozônio na região da Alta Troposfera e Baixa Estratosfera (do inglês Upper Troposphere and Lower Stratosphere - UTLS), como, por exemplo, a mudança da altura da tropopausa dinâmica, governada pelas circulações de grande escala (Zubiaurre e Calvo, 2012).

Os eventos de ENOS na fase El Niño favorecem aumento da convecção e perturbações de ondas na região do Pacífico oriental, provocadores trens de ondas de Rossby que influenciam a altura da tropopausa em latitudes médias e em parte da região tropical, o que por consequência provoca alterações nas concentrações da CTO. Este desvio nos padrões atmosféricos favorece a geração de anomalias significativas dos valores de CTO que induz à subsidência de ar estratosférico para níveis mais baixos e também fazendo que haja aumento das concentrações de CTO nos extratrópicos e uma diminuição na região do NEB.

Uma possível explicação para a maior concentração da CTO em região tropical durante eventos Modoki, quando comparado a eventos Canônico, pode residir na variação da distribuição vertical das anomalias de ozônio. Segundo Xie et al. (2012; 2014), eventos El Niño Modoki conduz a uma diminuição do ozônio na estratosfera tropical a qual está inclusa a região do NEB.

\section{Conclusões}

Em resumo, neste estudo foram apresentadas as consequências das atuações de diferentes modalidades do El Niño de Oscilação Sul, Canônico e Modoki, nas variações da CTO sobre a região do NEB no período entre 1997 a 


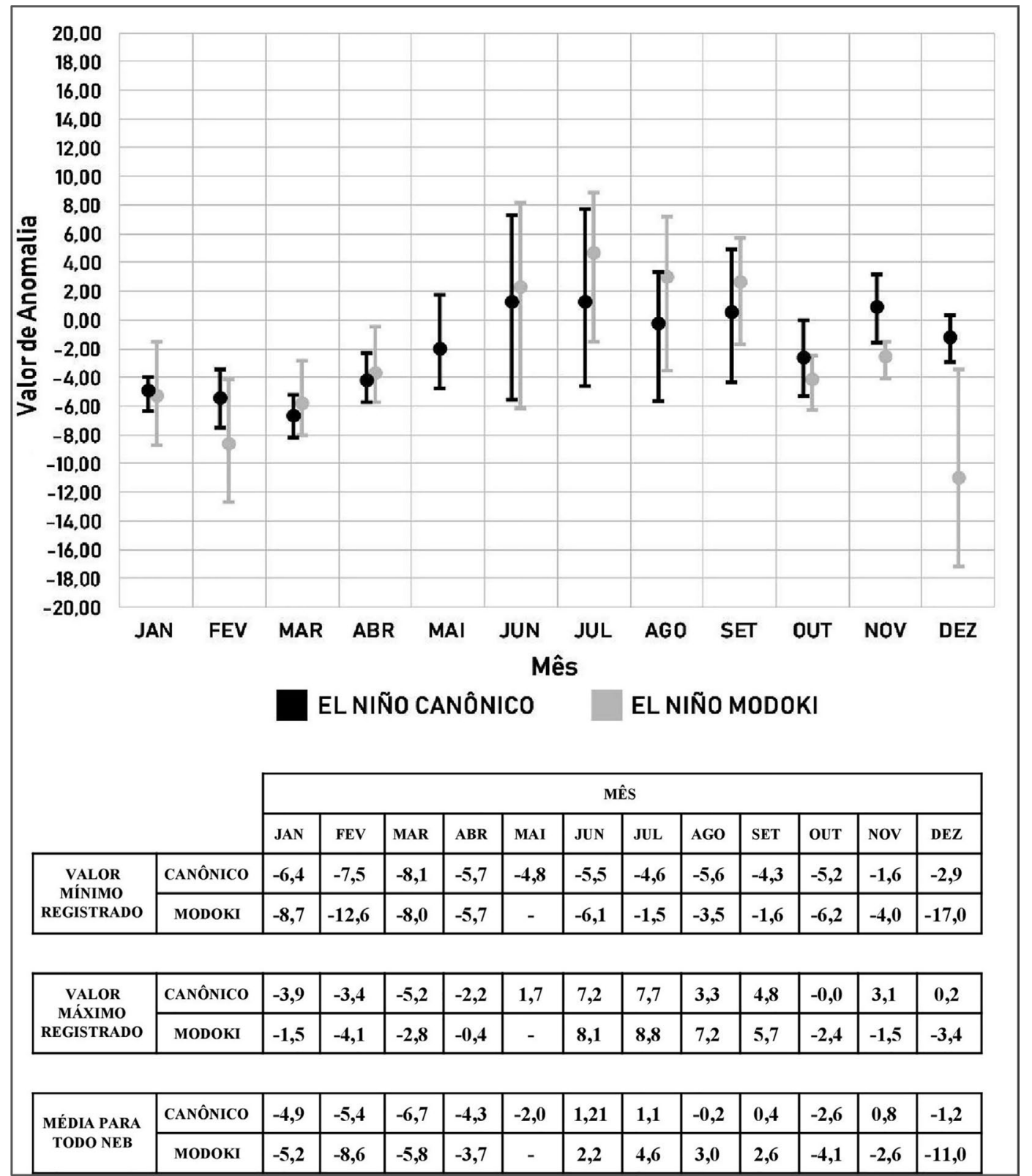

Figura 7 - Comparativo de valores mensais médios, máximos e mínimos de CTO para períodos sob influência de El Niño Canônico e Modoki. No gráfico superior, círculos preenchidos representam valores médios mensais e barras indicam valores máximos e mínimos registrados para os respectivos meses.

2018. Também através desse estudo foi possível compreender com maiores particularidades as variações da CTO sobre o NEB, obtendo um panorama com maior detalhamento do comportamento nesta região. No trimestre DJF, o litoral leste do NEB apresenta valores médios de CTO superiores à região oeste. Estes valores apresentam diminuição em todo NEB durante o trimestre MAM alcançando as menores médias para todo ano, no entanto, com maior intensidade nas regiões em direção ao centro do continente, oeste da Bahia, e com menor intensidade no litoral norte. Essa informação é preciosa pois é revelado que o trimestre MAM é mais perigoso à saúde humana quanto a exposição à radiação solar direta quando comparado a outros períodos do ano, sendo ainda mais alarmante para os que residem em áreas interioranas. No trimestre seguinte os valores aumentam e em SON atinge as maiores médias para todos os quadrantes, resguardando com maior intensidade toda a população do NEB.

A análise de ondeletas de cada grupo de quadrantes obtidos durante o estudo mostrou que todos apresentam um forte sinal de ciclo com duração de 12 meses, a variação anual da CTO. Aqueles quadrantes mais próximos ao equador apresentam fortes sinais de ciclo com período de duração de 6 meses, escala intrasazonal. Esse ciclo tam- 
bém está presente, porém mais fraco, nos grupos mais ao sul do NEB. Nos grupos A, B e C um forte sinal de ciclo com 2-3 anos de duração foi observado, ressaltando que esses grupos são os mais próximos ao equador.

A partir dos resultados é possível afirmar que fenômenos El Niño - Canônico e Modoki, grande influenciador nas características atmosféricas do NEB trazendo chuvas e secas, também modula, com relevância, as concentrações de ozônio na atmosfera desta região permitindo que mais ou menos radiação atinja a superfície terrestre. As médias das anomalias para todo período neutro apresentam valores de pouca intensidade, predominantemente positivos, onde cerca de $48 \%$ dos quadrantes registram anomalias positivas e $52 \%$ anomalias negativas. Em ambas modalidades de El Niño, Canônico e Modoki, há predominância de anomalias negativas, no entanto, na região mais ao norte do NEB há registro de predomínio de anomalias positivas nos trimestres estudados, DJF e JJA. Análises dos períodos sem atuação de ENOS e de todo período de estudo (de 1997 a 2018) apresentam sinais de anomalia opostos aos das modalidades Canônico e Modoki em ambos os trimestres. Podemos então concluir a partir das análises realizadas que fenômenos El Niño, de ambas modalidades, afetam a CTO, predominantemente diminuindo seus valores e expondo a população do NEB à maiores doses de radiação UV.

Estes resultados incentivam futuras pesquisas envolvendo outros modos de variabilidade atmosférica que atuam sobre a região com intuito de compreender se estes também influenciam nas concentrações de CTO.

\section{Referências}

ABALOS, M.; LEGRAS, B.; PLOEGER, F.; RANDEL, W.J. Evaluating the advective Brewer-Dobson circulation in three reanalyses for the period 1979-2012. Journal of Geophysical Research Atmospheres, v. 120, n. 15, p. 7534-7554, 2015.

ALBERS, J.R.; PERLWITZ, J.; BUTLER, A.H.; BIRNER, T.; KILADIS, G.N.; LAWRENCE, Z.D.; MANNEY, G.L.; LANGFORD, A.O.; DIAS, J. Mechanisms governing interannual variability of stratosphere-to-troposphere ozone transport. Journal of Geophysical Research Atmospheres, v. 123, n. 1, p. 234-260, 2018.

ALLAN, R.J.; LINDERSAY, J.; PARKER, D. EI Niño Southern Oscillation and Climate Variability. Collingwood: CSIRO Publishing, 1996.

AMBRIZZI, T. El Niño Oscilação Sul e Teleconexões Atmosféricas no Hemisfério Austral. São Paulo: USP/IAG, 2003.

BALDWIN, M.P.; GRAY, L.J.; DUNKERTON, T.J.; HAMILTON, K.; HAYNES, P.H.; RANDEL, W.J.; HOLTON, J.R.; ALEXANDER, M.J.; HIROTA, I.; HORINOUCHI, T.; JONES, D.B.A.; KENNERSLEY, J.S.; MARQUARDT, C.; SATO, K.; TAKAHASHI, M. The quasi-biennial oscillation. Reviews of Geophysics, v. 39, n. 2, p. 179-229, 2001.
BRAESICKE, P.; MORGENSTERN, O.; PYLE, J. Might dimming the sun change atmospheric ENSO teleconnections as we know them?. Atmospheric Science Letters, v. 12, n. 2, p. 184-188, 2011.

CALVO, N.; GARCIA, R.R.; RANDEL, W.J.; MARSH, D.R. Dynamical mechanism for the increase in tropical upwelling in the lowermost tropical stratosphere during warm ENSO events. Journal Atmospheric Sciences, v. 67, n. 7, p. 2331-2340, 2010.

CHEHADE, W.; WEBER, M.; BURROWS, J.P. Total ozone trends and variability during 1979-2012 from merged data sets of various satellites. Atmospheric Chemistry and Physics, v. 14, n. 13, p. 7059-7074, 2014.

DAVIS, S.M.; HEGGLIN, M.I.; FUJIWARA, M.; DRAGANI, R.; HARADA, Y.; KOBAYASHI, C.; LONG, C.; MANNEY, G.L.; NASH, E.R.; POTTER, G.L.; TEGTMEIER, S.; WANG, T.; WARGAN, K.; WRIGHT, J.S. Assessment of upper tropospheric and stratospheric water vapor and ozone in reanalyses as part of S-RIP. Atmospheric Chemistry and Physics, v. 17, n. 20, p. 12743-12778, 2017.

DE ARTIGAS, M.Z; FERNANDEZ, P. Trends in total ozone and the effect of the equatorial zonal wind QBO. Journal of Atmospheric and Solar-Terrestrial Physics, v. 72, n. 7, p. $565-569,2010$.

DIALLO, M.; RIESE, M.; BIRNER, T.; KONOPKA, P.; MÜLLER, R.; HEGGLIN, M.I.; SANTEE, M.L.; BALDWIN, M.; LEGRAS, B.; PLOEGER, F. Response of stratospheric water vapor and ozone to the unusual timing of El Niño and the QBO disruption in 2015-2016. Atmospheric Chemistry and Physics, v. 18, n. 17, p. 13055-13073, 2018.

DIALLO, M.; KONOPKA, P.; SANTEE, M.; MÜLLER, R.; TAO, M.; WALKER, K.; LEGRAS, B.; RIESE, M.; ERN, M.; PLOEGER, F. Structural changes in the shallow and transition branch of the Brewer-Dobson circulation induced by El Niño. Atmospheric Chemistry and Physics, v. 19, n. 1, p. 425-446, 2019.

DIAS NUNES, M. Influência da Coluna Total de Ozônio na Variabilidade da Radiação Ultravioleta Sobre o Sul da América do Sul. Dissertação de Mestrado em Meteorologia, Programa de Pós-graduação em Meteorologia, Universidade Federal de Pelotas, Pelotas, 110 f., 2017.

DIAS NUNES, M.; MARIANO, G.L.; ALONSO, M.F. Variabilidade espaço-temporal da coluna total de ozônio e sua relação com a radiação ultravioleta na América do Sul. Revista Brasileira de Geografia Física (in press).

DIVAKARLA, M.; BARNET, C.; GOLDBERG, M.; MADDY, E.; IRION, F.; NEWCHURCH, M.; LIU, X.; WOLF, W.; FLYNN, L.; LABOW, G; XIONG, X.; WEI, J.; ZHOU, L. Evaluation of Atmospheric Infrared Sounder ozone profiles and total ozone retrievals with matched ozonesonde measurements, ECMWF ozone data, and Ozone Monitoring Instrument retrievals. Journal of Geophysical Research, v. 113, n. D15, 2008.

GILFORD, D.M.; SOLOMON, S. Radiative effects of stratospheric seasonal cycles in the tropical upper troposphere and lower stratosphere. Journal of Climate, v. 30, n. 8, p. 2769-2783, 2017.

GONZALEZ, P.L.; POLVANI, L.M.; SEAGER, R.; CORREA, G.J. Stratospheric ozone depletion: a key driver of recent 
precipitation trends in South Eastern South America. Climate Dynamics, v. 42, n. 7-8, p. 1775-1792, 2014.

GRIMM, A.M. The El Niño impact on the summer monsoon in Brazil: Regional processes versus remote influences. Journal of Climate, v. 16, n. 2, p. 263-280, 2003.

GRIMM, A.M. How do La Niña events disturb the summer monsoon system in Brazil? Climate Dynamics, v. 22, n. 2, p. 123-138, 2004.

GRISE, K.M.; POLVANI, L.M.; TSELIOUDIS, G.; WU, Y.; ZELINKA, M.D. The ozone hole indirect effect: Cloudradiative anomalies accompanying the poleward shift of the eddy-driven jet in the Southern Hemisphere. Geophysical Research Letters, v. 40, n. 14, p. 3688-3692, 2013.

GRISE, K.M.; SON, S.W.; CORREA, G.J.; POLVANI, L.M. The response of extratropical cyclones in the Southern Hemisphere to stratospheric ozone depletion in the 20th century. Atmospheric Science Letters, v. 15, n. 1, p. 29-36, 2014.

KANG, S.M.; POLVANI, L.M.; FYFE, J.C.; SIGMOND, M. Impact of polar ozone depletion on subtropical precipitation. Science, v. 332, n. 6032, p. 951-954, 2011.

KIM, J.; CHO, H.K.; MOK, J.; YOO, H.D.; CHO, N. Effects of ozone and aerosol on surface UV radiation variability. Journal of Photochemistry and Photobiology B: Biology, v. 119, n. 1, p. 46-51, 2013.

KIRCHHOFF, V.W.J.H.; ECHER, E.; LEME, N.P.; SILVA, A.A. A variação sazonal da radiação ultravioleta solar biologicamente ativa. Revista Brasileira de Geofísica, v. 18, n. 1, p. 63-74, 2000.

LIMA, D.M.C.; MONTEIRO, D.R.S.; MARIANO, E.V.C.; MARIANO, G.L. Variação da coluna total de ozônio sobre o nordeste brasileiro. In: Anais $1^{\circ}$ Workshop Brasileiro de Micrometeorologia, Santa Maria: UFSM, 2018.

LOPES, Á.P.; COSTA, M.J.S. Comparação entre métodos de aproximação numérica utilizando o programa MATLAB. Revista Margens Interdisciplinar, v. 11, n. 17, p. 14, 2018.

LOPO, A.B.; SPYRIDES, M.H.C.; LUCIO, P.S.; SIGRÓ, J. Radiação ultravioleta, ozônio total e aerossóis na cidade de Natal-RN. HOLOS, v. 6, n. 3, p. 3-21, 2013.

MANATSA, D.; MUKWADA, G. A connection from stratospheric ozone to El Niño-Southern Oscillation. Science Reports, v. 7, n. 1, p. 1-10, 2017.

MING, A.; MAYCOCK, A.C.; HITCHCOCK, P.; HAYNES, P. The radiative role of ozone and water vapour in the temperature annual cycle in the tropical tropopause layer. Atmospheric Chemistry and Physics, v. 17, n. 9, p. 56775701, 2017.

NCEP - National Centers for Environmental Prediction. El Niño - Southern Oscillation (ENSO), 2018. Disponível em: https://bit.ly/2NdZEVA. Acesso em 19 de junho de 2020.

NOWACK, P.J.; BRAESICKE, P.; LUKE ABRAHAM, N.; PYLE, J.A. On the role of ozone feedback in the ENSO amplitude response under global warming. Geophysical Research Letters, v. 44, n. 8, p. 3858-3866, 2017.

OLIVEIRA, G.O.; SATYAMURTY, P. O El Niño de 1997/98: Evolução e Impactos no Brasil. In: Anais do 10 Congresso Brasileiro de Meteorologia, Brasília, 1998.

PERES, Lucas Vaz. Efeito Secundário do Buraco de Ozônio Antártico sobre o Sul do Brasil. Dissertação de Mestrado em Meteorologia, Programa de Pós-Graduação em Meteorologia, Universidade Federal de Santa Maria, Santa Maria, 178 f., 2013.

PERES, L.V.; BENCHERIF, H.; MBATHA, N.; SCHUCH, A.P.; TOIHIR, A.M.; BÈGUE, N.; PORTAFAIX, T.; ANABOR, V.; PINHEIRO, D.K; LEME, N.M.P.; BAGESTON, J.V.; SCHUCH, N.J. Measurements of the total ozone column using a Brewer spectrophotometer and TOMS and OMI satellite instruments over the Southern Space Observatory in Brazil. Annales Geophysicae, v. 35, n. 1, p. 25-37, 2017.

PHILANDER, S.G. EI Niño, La Niña, and Southern Oscillation. San Diego: Academy Press, 1990.

POLVANI, L.M.; PREVIDI, M.; DESER, C. Large cancellation, due to ozone recovery, of future Southern Hemisphere atmospheric circulation trends. Geophysical Research Letters, v. 38, L04707, 2011.

REED, R.J.; CAMPBELL, W.J.; RASMUSSEN, L.A.; ROGERS, D.G. Evidence of downward propagating annual wind reversal in the equatorial stratosphere. Journal of Geophysical Research, v. 66, n. 3, p. 813-818, 1961.

REID, G.C.: GAGE, K.S. Inter-annual variations in the height of the tropical tropopause. Journal of Geophysical Research, v. 90, n. D3, p. 5629-5635, 1985.

REID, G.C. Seasonal and interannual temperature variations in the tropical stratosphere. Journal of Geophysical Research, v. 99, n. D9, p. 18923-18932, 1994.

SAHAI, Y.; KIRCHHOFF, V.W.J.H.; LERNE, N.P.; CASICCIA, C. Total ozone trends in the tropics. Journal of Geophysical Research: Atmospheres, v. 105, n. D15, p. 1982319828, 2000.

SOLOMON, S. Stratospheric ozone depletion: A review of concepts and history. Reviews of Geophysics., v. 37, n. 3, p. 275-316, 1999.

SOUSA, C.T.; LEME, N.M.P.; MARTINS, M.P.P.; SILVA, F.R.; PENHA, T.L.B.; RODRIGUES, N.L.; SILVA E.L.; HOELZEMANN, J.J. Ozone trends on equatorial and tropical regions of South America using Dobson spectrophotometer, TOMS and OMI satellites instruments. Journal of Atmospheric and Solar-Terrestrial Physics, v. 203, 105272, 2020.

STEINBRECHT, W.; HEGGLIN, M.I.; HARRIS, N.; WEBER, M. Is global ozone recovering? Comptes Rendus Geoscience, v. 350, n. 7, p. 368-375, 2018.

TAKAHASHI, K., MONTECINOS, A., GOUBANOVA, K., DEWITTE, B. ENSO regimes: Reinterpreting the canonical and Modoki El Niño. Geophysical Research Letters, v. 38, L10704, 2011.

TOIHIR, A.M.; PORTAFAIX, T.; SIVAKUMAR, V.; BENCHERIF, H.; PAZMIÑO, A.; BÈNGUE, N. Variability and trend in ozone over the southern tropics and subtropics. Annales Geophysicae, v. 36, n. 2, p. 381-404, 2018.

TORRENCE, C.; COMPO, G.P. A practical guide to wavelet analysis. Bulletin of the American Meteorological Society, v. 79, n. 1, p. 61-78, 1998.

TIAN, W.; LI, Y.; XIE, F.; ZHANG, J.; CHIPPERFIELD, M.P.; FENG, W.; HU, Y.; ZHAO, S.; ZHOU, X.; YANG, Y.; MA, $\mathrm{X}$. The relationship between lower-stratospheric ozone at southern high latitudes and sea surface temperature in the 
East Asian marginal seas in austral spring. Atmospheric Chemistry and Physics, v. 17, n. 11, p. 6705-6722, 2017.

WANG, J.; PAWSON, S.; TIAN, B.; LIANG, M.C.; SHIA, R.L.; YUNG, Y.L.; JIANG, X. El Niño-Southern Oscillation in tropical and midlatitude column ozone. Journal Atmospheric Sciences, v. 68, n. 9, p. 1911-1921, 2011.

WEBER, M.; COLDEWEY-EGBERS, M.; FIOLETOV, V.E.; FRITH, S.; WILD, J.; BURROWS, J.P.; LONG C.S.; LOYOLA, D. Total ozone trends from 1979 to 2016 derived from five merged observational datasets-the emergence into ozone recovery. Atmospheric Chemistry and Physics, v. 18, n. 3, p. 2097-2117, 2018.

WILKS, D; Statistical Methods in the Atmospheric Sciences, v. 10, 3ed, Cambridge: Academic Press, 704 p., 2011.

XIE, F.; TIAN, W.; CHIPPERFIELD, M.P. Radiative effect of ozone change on stratosphere-troposphere exchange. Journal Geophysical Research, v. 113, n. D7, 2008.

XIE, F.; LI, J.; TIAN, W., FENG, J.; HUO, Y. Signals of El Niño Modoki in the tropical tropopause layer and stratosphere. Atmospheric Chemistry \& Physics, v. 12, n. 11, p. 52595273, 2012.

XIE, F.; LI, J.; TIAN, W.; ZHANG, J.; SUN, C. The relative impacts of El Niño Modoki, canonical El Niño, and QBO on tropical ozone changes since the 1980s. Environmental Research Letters, v. 9, 064020, 2014.
XIE, F.; LI, J.; TIAN, W.; ZHANG, J.; SHU, J. The impacts of two types of El Niño on global ozone variations in the last three decades. Advances in Atmospheric Sciences, v. 31, n. 5, p. 1113-1126, 2014.

ZHANG, J.; TIAN, W.; WANG, Z.; XIE, F.; WANG, F. The influence of ENSO on northern midlatitude ozone during the winter to spring transition. Journal of Climate, v. 28, n. 12, p. 4774-4793, 2015.

ZUBIAURRE, I.; CALVO, N. The El Niño-Southern Oscillation (ENSO) Modoki signal in the stratosphere. Journal of Geophysical Research: Atmospheres, v. 117, n. D4, 2012.

\section{Endereços de Internet}

GIOVANNI: https://giovanni.gsfc.nasa.gov/giovanni/

JAMSTEC. http://www.jamstec.go.jp/aplinfo/sintexf/e/elnmo doki/data.html

NOAA. https://origin.cpc.ncep.noaa.gov/products/analysis_moni toring/ensostuff/ONI_v5.php

License information: This is an open-access article distributed under the terms of the Creative Commons Attribution License (type CC-BY), which permits unrestricted use, distribution and reproduction in any medium, provided the original article is properly cited. 